\title{
Narrative Identity Processing of Difficult Life \\ Experiences: Pathways of Personality \\ Development and Positive Self- \\ Transformation in Adulthood
}

\author{
Jennifer L. Pals \\ Northwestern University
}

\begin{abstract}
Difficult life experiences in adulthood constitute a challenge to the narrative construction of identity. Individual differences in how adults respond to this challenge were conceptualized in terms of two dimensions of narrative identity processing: exploratory narrative processing and coherent positive resolution. These dimensions, coded from narratives of difficult experiences reported by the women of the Mills Longitudinal Study (Helson, 1967) at age 52, were expected to be related to personality traits and to have implications for pathways of personality development and physical health. First, the exploratory narrative processing of difficult experiences mediated the relationship between the trait of coping openness in young adulthood (age 21) and the outcome of maturity in late midlife (age 61). Second, coherent positive resolution predicted increasing ego-resiliency between young adulthood
\end{abstract}

This research was supported by a National Science Foundation Predoctoral Fellowship and by National Institute of Mental Health Grant MH-43948. I thank Ravenna Helson and Oliver John for their mentorship, feedback, and support during every stage of this research. I also thank Dan McAdams and Jefferson Singer for the thoughtful and very helpful comments they provided on drafts of this article. Finally, I express my appreciation to my research assistants who completed the narrative coding used in this study, Amy Busch, Meg Jay, and Lucy Rimalower.

Correspondence concerning this article should be addressed to Jennifer L. Pals, Foley Center for the Study of Lives, Northwestern University, 2120 Campus Dr., Evanston, IL 60208. E-mail: j-pals@northwestern.edu.

Journal of Personality 74:4, August 2006

(C) 2006, Copyright the Authors

Journal compilation (C) 2006, Blackwell Publishing, Inc.

DOI: $10.1111 / \mathrm{j} .1467-6494.2006 .00403 . \mathrm{X}$ 
and midlife (age 52), and this pattern of increasing ego-resiliency, in turn, mediated the relationship between coherent positive resolution and life satisfaction in late midlife. Finally, the integration of exploratory narrative processing and coherent positive resolution predicted positive self-transformation within narratives of difficult experiences. In turn, positive self-transformation uniquely predicted optimal development (composite of maturity and life satisfaction) and physical health.

I knew I reached an emotional bottom that year ... but I began making a stable life again, as a more stable independent person... . It was a period full of pain, experimentation, and growth, but in retrospect it was necessary for me to become anything like the woman I am today.

This narrative excerpt is a middle-aged woman's response to being asked to tell a story about the most difficult and identity-challenging time of her adult life. Although she acknowledges the emotional pain of this experience, it is noteworthy that she has not attempted to distance herself from it. Rather, she has fully embraced the experience and explored its meaning in her life, constructing a powerful story of resilience and self-transformation that is central to how she defines herself today. This example is consistent with a growing literature within personality psychology that asserts that (a) identity in adulthood takes the shape of a coherent narrative or life story that integrates interpretations of the past with the present self and provides life with meaning and purpose, and (b) the processes of constructing, revising, and living in accordance with this narrative identity over time are central to personality functioning, development, and well-being (McAdams, 2001; Singer, 2004; Singer \& Blagov, 2004). Building on this literature, the current study examines the idea that individual differences in how adults narrate their most difficult experiences reflect processes and outcomes of narrative identity construction that are rooted in pathways of personality development and have implications over time for important outcomes, including maturity, subjective well-being, and physical health.

Individual Differences in the Narrative Identity Processing of Difficult Life Experiences: Relationships to Maturity and Subjective Well-Being

A central assumption of the current theoretical framework is that narrative identity is made up of memories of emotionally significant 
experiences that are interpreted to contain self-defining meaning and integrated into the broader themes and patterns that comprise the life story as a whole (McAdams, 2001; Pillemer, 2001; Singer \& Blagov, 2004; Singer \& Salovey, 1993). Some memories fit neatly into the existing story line that has already been constructed, thus providing identity continuity, whereas others challenge the story line and invite identity questioning and transformation (McAdams, 1985). It may be argued that difficult experiences in adulthood typically fall into the latter category of identity challenge. For example, the experiences of divorce, the loss of a job, and the diagnosis of a serious illness, while experientially distinct, are similar in that they all have the potential to challenge the life story that had been providing a person's life with coherence, meaning, and purpose (Cohler, 1991; Janoff-Bulman, 1992). Thus, one level at which adults must respond to difficult life experiences is the level of challenge to narrative identity. The term narrative identity processing is used here to refer to the ongoing task of narrating and interpreting past experiences and incorporating them into the life story as lasting narrative products (see Singer \& Blagov, 2004). Several recent studies suggest that systematic individual differences in the narrative identity processing of difficult life experiences organize around the distinct correlates of maturity and subjective well-being.

Exploratory narrative processing and maturity. First, recent research suggests that personality maturity is associated with a set of narrative characteristics that reflect exploratory narrative processing, broadly defined as the active, engaged effort on the part of the narrator to explore, reflect on, or analyze a difficult experience with an openness to learning from it and incorporating a sense of change into the life story. Although there are many ways to define maturity (e.g., Helson \& Wink, 1987), the definition that is of primary interest here is the level of awareness and cognitive complexity one brings to selfunderstanding and affective experience. This aspect of maturity, alternatively labeled intrapsychic differentiation (Helson \& Wink, 1987), social-cognitive maturity (Bauer \& McAdams, 2004), and affect complexity (Labouvie-Vief \& Medler, 2002) and typically operationalized with Loevinger's (1976) levels of ego development, has been associated with several narrative characteristics suggestive of exploratory narrative processing, including (a) accommodation (exploration and paradigmatic shifts in thinking) within parents' 
narratives of finding out a child has Down syndrome (King, Scollon, Ramsay, \& Williams, 2000), (b) searching for and creating new perspectives within adults' narratives of changing careers and religions (Bauer \& McAdams, 2004), (c) the vivid elaboration of selves that have been lost within women's narratives of midlife divorce (King \& Raspin, 2004), and (d) concerted questioning within students' narratives of a religious identity crisis (McAdams, Booth, \& Selvik, 1981). Consistent with these findings, two indicators of exploratory narrative processing were coded from the narratives in the current study: (1) the richness and complexity of narrative elaboration (i.e., the narrator's engagement with processing the experience), and (2) how open to change and exploratory versus closed to change and minimizing the narrator is in how she describes the experience and makes sense of its impact over time.

Coherent positive resolution and subjective well-being. Recent research suggests that subjective well-being - defined by Diener, Suh, Lucas, and Smith (1999) as life satisfaction, the presence of positive affect, and the absence of negative affect - may be associated with a pattern of coherent positive resolution within narratives of difficult life experiences. Coherent positive resolution is defined here as the construction of a coherent and complete story of a difficult event that ends positively, conveying a sense of emotional resolution or closure. ${ }^{1}$ The two key ingredients of this pattern - narrative coherence and the positive resolution of a negative scene- have both been associated with several indicators of subjective well-being. First, within the context of narratives of difficult life experiences, King et al. (2000) showed that foreshadowing (a form of narrative coherence), a sense of closure, and happy endings within parents' narratives of finding out a child has Down syndrome were associated with a composite measure of subjective well-being. Second, at the broader level of the narration of the life story, Baerger and McAdams (1999) showed that the coherent narration of life story scenes (e.g., clear structure, integration of information into a unified and

1. The term resolution does not refer to the objective resolution of difficult circumstances in a person's life. Many events never get completely resolved, and their effects may linger on in various ways. In contrast, coherent positive resolution refers to a sense of narrative completion that releases the person from the emotional grip of the event and allows the life story to move forward. 
resolved story line) was positively associated with life satisfaction and negatively with depression. In addition, individuals whose life stories contained a high density of redemption sequences - scenes in which a negative experience is followed with a positive outcomescored higher on several indicators of subjective well-being than those with less redemption in their stories (McAdams, Reynolds, Lewis, Patten, \& Bowman, 2001). Taken together, these findings suggest that subjective well-being is associated with the capacity to construct a coherently structured story about a difficult experience, the ending of which emphasizes the restoration of the positive in the person's life and a sense that the person has moved on emotionally. Several indicators of coherent positive resolution were coded from the narratives in the current study, including emotional resolution, the presence of a coherently structured conclusion, and the valence of the narrative ending.

\section{Narrative Identity Processing and Pathways of Personality Development}

Building on the findings presented above, the main goal of the current study is to articulate the life span-developmental dynamics of narrative identity construction by demonstrating the roles of exploratory narrative processing and coherent positive resolution in two distinct pathways of personality development - the path towards increasing complexity, self-understanding, wisdom, inner growth, and emotional sophistication captured by maturity and the path towards feeling good about oneself and one's life captured by subjective wellbeing (e.g., Bauer, McAdams, \& Sakaeda, 2005; Helson \& Srivastava, 2001; Helson \& Wink, 1987; King, 2001; Labouvie-Vief \& Medler, 2002). In doing so, this study expands upon the existing narrative identity literature in two ways. First, it incorporates personality traits into the dynamics of narrative identity construction. Although narrative identity has been described as a distinct level of personality (McAdams, 2001) and an organizing mechanism within the personality system (Singer \& Blagov, 2004), little empirical research has explicitly examined connections between traits and narrative (see Bauer et al., 2005, and McAdams et al., 2004, for notable exceptions), particularly with a developmental and process-oriented perspective. As described below, the trait constructs featured here in 
connection with the narrative identity processing of difficult experiences are coping openness and ego-resiliency.

A second advance of this study over most previous research on narrative identity is the use of a long-term longitudinal design. Although narrative identity constitutes a life span-developmental approach to personality (Singer, 2004), the recent burst of empirical research in this area has been primarily retrospective and either cross-sectional or short-term longitudinal in design. In contrast, the ongoing Mills Longitudinal Study of Women (see Helson, 1967; Helson \& Srivastava, 2001; Helson \& Wink, 1987) that was used in the current investigation spans from young adulthood (age 21) through to late midlife (age 61), with narratives of the difficult experiences reported at age 52. This 40-year, multiwave design allows for the examination of (a) how narrative identity processing relates to personality traits as measured both prior to (age 21) and after the occurrence of the difficult life experiences being narrated (age 52) and (b) more dynamically, how these trait-narrative associations are involved in pathways of development that culminate with the outcomes of maturity and subjective well-being (age 61). The relationships hypothesized to comprise these developmental pathways are described below.

Coping openness, exploratory narrative processing, and maturity. The first set of hypotheses examined in this study involves interrelations among exploratory narrative processing, the trait of coping openness, and the developmental outcome of maturity. Previous research suggests that the exploratory narrative processing of difficult experiences may be facilitated by the trait of coping openness, which captures the extent to which people are open to and tolerant of (as opposed to defended against) the negative, ambiguous, and complex thoughts and feelings generated by difficult experiences (see Haan, 1977; Labouvie-Vief \& Medler, 2002). For example, openness to feelings was associated with an identity style of interpreting life experiences in terms of their capacity to provide new information about the self (Berzonsky \& Sullivan, 1992), and tolerance of ambiguity predicted greater dynamic complexity and openness to change in narrative representations of self (Labouvie-Vief \& Medler, 2002). In contrast, a repressive coping style (i.e., low coping openness) has been associated with limited retrieval of negative emotional experiences about the self (Davis, 1987, 1995) and low specificity 
within self-defining memories (Blagov \& Singer, 2004), both of which suggest narrative identity processing that is minimally engaged and geared more towards self-distancing than exploration. Taken together, these findings suggest that the thoughts and feelings one experiences by way of being open to as opposed to defended against difficult experiences will provide the "necessary fuel" for exploratory narrative processing to occur. A person's level of coping openness should therefore constitute a stable aspect of personality that shapes the path of narrative identity construction over the course of adulthood through the active stimulation (in contrast to defensive minimization) of the exploratory narrative processing of difficult experiences. Thus, it was hypothesized that, beginning in young adulthood (age 21) and continuing through to midlife (age 52), coping openness will predict exploratory processing within narratives of difficult experiences (age 52).

Further elaborating this pathway of development, coping openness is expected to lead to the development of maturity in adulthood through its stimulation of exploratory narrative processing. In other words, adults who possess the capacity to cope openly will experience identity-challenging difficulties in a way that facilitates exploratory narrative processing, and this exploratory narrative processing, in turn, will generate greater self-understanding, emotional awareness, and complexity and enhance maturity. In contrast, those who cope in a more defended manner will cut themselves off from the complexity and depth of thought and emotion around difficult experiences, therefore limiting exploratory narrative processing and the development of maturity. Thus, exploratory narrative processing, as a developmental process that enriches narrative identity over time, should mediate the relationship between coping openness in early adulthood (age 21) and maturity in late midlife (age 61).

Ego-resiliency, coherent positive resolution, and life satisfaction. The second set of hypotheses examines relations among coherent positive resolution, the trait of ego-resiliency, and one component of subjective well-being, life satisfaction. Previous research on ego-resiliency, broadly defined as the extent to which people are able to adapt to challenging life circumstances flexibly and restore positive affect in response to difficult emotional experiences (Block \& Block, 1980; Klohnen, 1996; Tugade \& Fredrickson, 2004), suggests that this trait may be closely associated with the capacity to narrate difficult 
experiences with coherent positive resolution. For example, individuals higher in ego-resiliency were more likely than their low egoresiliency counterparts to find positive meaning in connection with negative life events (Tugade \& Fredrickson, 2004). In addition, a previous study using the Mills sample (Pals, 1999) showed that ego-resiliency at age 21 predicted the construction of a coherent and positive identity narrative of the difficult transition from college into young adulthood, and this positive identity narrative, in turn, predicted a relative increase in ego-resiliency from age 21 to age 27 .

Building on the findings described above, it is hypothesized that coherent positive resolution, as an effective and healthy narrative identity response to difficult experiences, should demonstrate a reciprocal relationship with ego-resiliency between young adulthood and midlife. On the one hand, the level of ego-resiliency exhibited in young adulthood should affect whether that person is able to navigate difficult experiences successfully and narrate them with coherent positive resolution. Thus, ego-resiliency at age 21 should predict coherent positive resolution at age 52 . On the other hand, the construction of coherent positive resolution should also contribute to the development of resiliency between young adulthood and midlife. This is expected to be true for two reasons. First, because coherent positive resolution promotes emotional closure and restores order and direction to the life story, the persistent lack of it could interfere with a person's capacity to cope with new challenges and lead to decreases in ego-resiliency over time. Second, if a person is able to narrate a difficult experience with coherent positive resolution, then the narrative of this particular experience may become an important self-defining memory (Singer \& Salovey, 1993) within the life story that serves as an active reminder of being able to overcome adversity in life. This memory of a capable, strengthened self should become an important part of narrative identity that enhances ego-resiliency as new challenges arise (see Singer, King, Green, \& Barr, 2002). Thus, coherent positive resolution should predict ego-resiliency at age 52, even after controlling for ego-resiliency at age 21 .

To articulate this pathway of development further, coherent positive resolution is expected to contribute to life satisfaction through its enhancement of ego-resiliency. Life satisfaction is the component of subjective well-being that is of primary interest in connection with narrative identity, because (a) it makes sense to expect an association 
between how people narrate life experiences and their overall satisfaction with their lives and (b) as people get older, how they evaluate their lives in the present may become increasingly influenced by how things have gone in the past. With respect to the narration of difficult experiences in particular, coherent positive resolution was expected to enhance life satisfaction by making people feel more resilient in the face of difficulties, thereby paving the way towards the construction of a satisfying life. In contrast, the lack of coherent positive resolution was expected to hinder life satisfaction by eroding resiliency in the face of difficulties, thereby allowing their damaging effects to loom large within the life story and culminate with the sense of a dissatisfying life. Thus, the association between coherent positive resolution (age 52) and life satisfaction (age 61) was expected to be mediated by an increase in ego-resiliency between age 21 and age 52 .

\section{Positive Self-Transformation, Optimal Development, and Physical Health}

The third set of hypotheses focuses on the idea that the most integrative, mature, and healthy form of narrative identity processing is achieved when exploratory narrative processing and coherent positive resolution come together within a narrative of a difficult experience. First, when adults engage in exploratory narrative processing by explicitly examining how an experience challenges the self and opens up possibilities for change, then the added effect of coherent positive resolution is expected to be a narrative ending that emphasizes an enduring sense of positive self-transformation within the life story. Thus, it is hypothesized that exploratory narrative processing and coherent positive resolution will jointly predict the theme of positive self-transformation within narratives of difficult experiences. Second, it is hypothesized further that positive self-transformation, as the lasting narrative product of mature and integrative narrative identity processing, will predict optimal development in late midlife (age 61), defined as the combination of being emotionally mature and satisfied with life. This hypothesis is consistent with King (2001), who argued that being both mature and happy is a developmental accomplishment of adulthood and that adults who achieve this combination tend to narrate their most difficult life experiences with a sense of active struggle, personal growth, and positive 
self-transformation. In King's (2001) words, happy and mature adults, by embracing the transformative possibilities of difficult life experiences, have taken "the hard road to the good life" (p. 51).

Finally, positive self-transformation was expected to enhance physical health in adulthood. As Pennebaker (1997) has demonstrated, individuals who write meaningfully about a traumatic event in their lives show better health outcomes than individuals who were limited to writing about trivial topics. Taking a narrative perspective on this phenomenon, Pennebaker and Seagal (1999) reported that those whose health benefited the most from writing were more "selfreflective, emotionally open, and thoughtful" (p. 1248) and used more words reflecting interpretations of causation, insight and the experience of positive affect than those who did not benefit. These findings suggest that writing about a traumatic event may improve physical health because it stimulates integrative narrative identity processing (i.e., exploratory narrative processing and coherent positive resolution) and the construction of positive self-transformation. Thus, it was hypothesized that women whose narratives contain the theme of positive self-transformation have engaged in the kind of integrative narrative identity processing that enhances physical health and should therefore display better physical health in late midlife than women who fail to see themselves as positively transformed by difficult experiences.

\section{METHOD}

\section{Participants}

The participants were college-educated, predominantly white women who were first assessed as seniors at Mills College in 1958 or 1960 (age 21) and studied subsequently at ages 27, 43, 52, and 61 (e.g., Helson, 1967; Helson \& Srivastava, 2001; Helson \& Wink, 1987). The current study focuses on 83 women, each of whom provided a narrative at age 52 of her most difficult time since college, and it employs data from the age 21, age 52, and age 61 assessments.

\section{Collection and Coding of Narratives of Difficult Life Experiences}

At age 52, participants were presented with the following written probe: "All of us have times of personal difficulty. Please think of the most unstable, confusing, troubled, or discouraging time in your life since college - the one with the most impact on your values, self-concept, and the 
way you look at the world. How old were you? How long did this period last?" (see also Helson, 1992). Eighty-seven women provided a meaningful narrative response to the question. Of those 87 women, four were excluded because their period of difficulty was ongoing at the time of the age 52 data collection. The remaining 83 narratives had a median length of 275 words and ranged in length from 27 to 5400 words. ${ }^{2}$ The life experiences reported in the women's narratives were wide-ranging in specific content but also quite representative of the typical identity-challenging difficulties of adult life. ${ }^{3}$ Nearly half were primarily focused on experiences having to do with marriage or romantic partnership, including divorce, extramarital affairs, problems of the partner that caused conflict, or difficulties adjusting to traditional gender roles. Another common experience was a time of poor mental health or emotional crisis brought about by combinations of multiple life stressors, including unhealthy relationships, financial problems, alcohol abuse, problems with children, etc. Other accounts focused on deaths of loved ones, work-related problems (e.g., being laid off), health problems, conflicts with children or parents, and difficult living situations. Finally, a few women reported they never had had a major difficult experience, instead emphasizing that their difficulties had been minor relative to the overall goodness of life.

A team of three judges independently coded each narrative on a series of 11 dimensions, 7 of which were selected for the current study for their level of reliability and their direct relevance to exploratory narrative processing, coherent positive resolution, and positive self-transformation. The training of the narrative coders first involved a series of meetings to discuss the conceptual definitions of the coding dimensions. Second, the judges coded the first 12 cases independently, taking notes on the reasoning behind their codes, and the coding dimensions were again discussed to establish clearer understanding. Finally, the judges independently coded the remaining 71 cases. A description of the

2. The 27-word response, though brief, was viewed to be codable for the present purposes, because it conveyed vivid information about the overwhelming lack of resolution experienced by the narrator. Because narrative length varied widely, all analyses were also conducted with narrative length included as a control variable. Narrative length did not alter any of the results.

3. Although the narrative probe asked for a description of a difficult time in life, the term difficult life experience has been used here, because the women's responses typically focused on a time that hinged on a fairly specific event, associated series of events, or set of circumstances that could accurately be described as a life experience. In terms of Conway and Pleydell-Pearce's (2000) hierarchical model of autobiographical knowledge, the vast majority of the narratives would be best categorized as general event memories, a middle level of autobiographical specificity that falls in between event-specific knowledge and lifetime periods. 
conceptual definition and rating scale used for each individual coding dimension is presented below, along with reliability and descriptive information. Reliability was assessed with (a) the average interjudge agreement, calculated by averaging the correlations between each pairing of the three judges (i.e., average $r$ ), and (b) Cronbach's alpha for the composite score created by averaging across the three judges' ratings.

Indicators of exploratory narrative processing. Two coding variables were selected to measure exploratory narrative processing: richness/ complexity of narrative elaboration and open-exploratory versus closedminimizing approach to coping. First, richness/complexity of narrative elaboration captured the extent to which the style of narration conveyed a willingness to tell the story and amplify its significance through elaborating on the impact of the experience and grappling with its difficulty and complexity. Richness/complexity of narrative style was rated on a 5-point scale on which a rating of 1 reflected a narrative style of being very closed to narrative richness/complexity, as illustrated by an unwilling narrator telling a minimal and unelaborated story, and a rating of 5 reflected a narrative style of being very open to narrative richness/complexity, as illustrated by a willing narrator telling a richly elaborated story. Average interjudge agreement for richness/complexity of narrative elaboration was .63 (.56-.68). Cronbach's alpha for the composite of the three judges was .83 , and the mean for the composite score across all 83 participants was $3.5(S D=1.2)$. Second, open-exploratory versus closedminimizing approach to coping contrasted the description of coping via opening the self up to exploring the impact of the experience and trying to gain something new from it (e.g., introspection, self-analysis, questioning) with coping via attempting to minimize the impact of the experience and distancing the self. Open versus closed coping response was rated on a 5point scale with a rating of 1 reflecting a very closed response and a rating of 5 reflecting a very open response. Average interjudge agreement for open-exploratory versus closed-minimizing approach to coping was .59 (.49-.70). Cronbach's alpha for the composite of the three judges was .81, and the mean for this composite was $3.2(S D=1.1)$.

Indicators of coherent positive resolution. Four coded variables were selected to measure coherent positive resolution: ending coherence, positive ending, negative ending, and emotional resolution. Ending coherence, rated on a 4-point scale, was defined as the extent to which a narrative has an identifiable and clear ending that signals to the reader that the story is complete. Narratives with coherent endings $(4=$ very coherent $)$ provided a clear sense of completion with a concluding section that included the individual's final, summarizing comments, whereas narratives with very 
incoherent endings $(1=$ very incoherent $)$ ended abruptly, uncertainly, or in the midst of details about the experience. Average interjudge agreement for ending coherence was .60 (.57-.61). Cronbach's alpha for the composite of the three judges was $.82(M=2.9, S D=.81)$. Positive ending and negative ending, two variables capturing the valence of the story's conclusion, were both rated on 3-point scales where 1 equaled not positive (or not negative), 2 equaled somewhat positive (or somewhat negative), and 3 equaled very positive (or very negative). Assessing positive and negative ending separately allowed for the differentiation between a neutral ending (low scores on both scales) and a mixed ending (high scores on both scales). The average interjudge agreement for positive ending was .72 (.70-.74) and for negative ending was .62 (.58-.65). Cronbach's alpha for the positive ending composite was $.89(M=2.2, S D=.65)$, and for the negative ending composite was $.83(M=1.7, S D=.57)$. The fourth indicator of coherent positive resolution, emotional resolution, was rated on a 4-point scale and reflected the extent to which the woman described herself as having achieved emotional closure so that her story was no longer "stuck" in the grip of the negative emotions generated by the experience. High scores $(4=$ very resolved $)$ were assigned to narratives reflecting a sense of closure, a renewed capacity to experience positive emotion, and a lack of unresolved issues and emotions; low scores $(1=$ very unresolved $)$ were assigned to narratives suggestive of low resolution and little progress towards resolution, and mid-range scores $(2=$ somewhat unresolved, $3=$ somewhat resolved) were assigned to narratives communicating a relative mix of progress towards and struggles with emotional resolution. Average interjudge agreement for emotional resolution was .68 (.64-.70). Cronbach's alpha for the emotional resolution composite was .86 $(M=2.8, S D=.90)$.

Scale construction. In order to demonstrate that the six coding dimensions described above indeed measured the narrative identity processing dimensions of exploratory narrative processing and coherent positive resolution, they were first submitted to a principal components analysis using varimax rotation. As expected, the principal components analysis yielded two factors with eigen values over 1 that together accounted for $81 \%$ of the variance. The first factor had an eigen value of 3.74 and accounted for $62 \%$ of the variance. The second factor had an eigen value of 1.12 and accounted for an additional $19 \%$ of the variance. The loadings for each variable from the rotated component matrix are reported in Table 1 along with their intercorrelations. As expected, the variables with the highest loadings on the first factor, Coherent Positive Resolution, were negative ending, positive ending, ending coherence, and emotional resolution. Also as expected, the variables with the highest 


\section{Table 1}

Intercorrelations and Factor Loadings for Coded Indicators of Narrative Identity Processing Dimensions $(\mathrm{N}=83)$

\begin{tabular}{|c|c|c|c|c|c|c|}
\hline $\begin{array}{l}\text { Narrative identity } \\
\text { processing indicators }\end{array}$ & 1 & 2 & 3 & 4 & 5 & 6 \\
\hline $\begin{array}{l}\text { 1. Richness/complexity of narrative } \\
\text { elaboration }\end{array}$ & & $.54 * *$ & $.44^{* * *}$ & -.09 & $.60 * *$ & $.34^{*}$ \\
\hline $\begin{array}{l}\text { 2. Open-exploratory vs. } \\
\text { closed-minimizing coping }\end{array}$ & & & $.48 * *$ & $-.26+$ & $.46^{* * *}$ & $.53 * *$ \\
\hline 3. Positive ending & & & & $-.67^{* * *}$ & $.76^{* * *}$ & $.77^{* * *}$ \\
\hline 4. Negative ending & & & & & $-.56 * *$ & $-.76^{* * *}$ \\
\hline 5. Ending coherence & & & & & & $.75^{* *}$ \\
\hline \multicolumn{7}{|l|}{ 6. Emotional resolution } \\
\hline \multicolumn{7}{|l|}{ Factor Loadings } \\
\hline Coherent positive resolution & .08 & .27 & .81 & -.94 & .69 & .88 \\
\hline Exploratory narrative processing & .92 & .76 & .41 & .04 & .57 & .32 \\
\hline
\end{tabular}

loading on the second factor, exploratory narrative processing, were richness/complexity of narrative elaboration and open-exploratory versus closed-minimizing coping. Contrary to expectation, ending coherence showed a substantial cross-loading on the exploratory narrative processing factor (.57). Despite some degree of overlap, however, the overall pattern presented in Table 1 demonstrates two distinct sources of variance that correspond to the hypothesized narrative identity processing dimensions.

Based on the results of the principal components analysis, ending coherence, positive ending, negative ending, and emotional resolution were used to create a scale for coherent positive resolution, while richness/ complexity of narrative elaboration and open-exploratory versus closedminimizing coping were used to create a scale for exploratory narrative processing. A two-step process was used to create a scale for coherent positive resolution. First, ending coherence, positive ending, and negative ending (reversed) were standardized and averaged together to create an index of the extent to which the narrative had a coherent and positively valenced ending. Second, this coherent and positive ending index was standardized and averaged together with the standardized version of emotional resolution. This two-step process was undertaken in order to weight equally the quality of the narrative ending and the emotional resolution of the event in the index of coherent positive resolution. This composite 
constituted the Coherent Positive Resolution scale. The two indices going into the scale were correlated .86 and the Cronbach's alpha for the scale was .92. The Exploratory Narrative Processing scale was created by averaging together richness/complexity of narrative elaboration and open-exploratory versus closed-minimizing coping (correlated .54). Cronbach's alpha for the Exploratory Narrative Processing scale was .70.

Consistent with the intercorrelations among the narrative indicators reported in Table 1, the Coherent Positive Resolution and Exploratory Narrative Processing scales were positively correlated with one another $(r=.51)$. This overlap between the two dimensions reflects an overarching "good story" effect in that the most developed and complete narratives integrate both dimensions of narrative identity processing. However, because one main focus of the study was on the distinct roles of exploratory narrative processing and coherent positive resolution in personality development, a second set of "pure" scores was created by regressing each on the other and saving the standardized residuals. Unless otherwise specified, this second set of scores was used in all subsequent analyses in order to isolate the unique roles of exploratory narrative processing and coherent positive resolution in pathways of development.

Positive self-transformation. A single rating of positive self-transformation also coded from the narratives by the three judges was used to capture the expected narrative product of exploratory narrative processing and coherent positive resolution. Positive self-transformation, rated on a 5-point scale, captured the extent to which the woman described a sense of enduring positive change within herself or her life as a result of the experience. Positive change could be expressed within a wide variety of identity-relevant domains, such as personality traits, self-understanding, wisdom, mental health, beliefs and values, and self-defining roles. High scores (rating of 5) reflected a well-developed description of positive selftransformation that was causally connected to the difficult experience and central to identity, whereas a rating of 1 reflected no evidence for positive self-transformation. Average interjudge agreement for positive self-transformation was .82 (.77-.87). The alpha for the positive self-transformation composite was $.93(M=2.7, S D=1.3)$. Consistent with hypotheses examined further below, positive self-transformation was positively correlated with both exploratory narrative processing $(r=.51)$ and coherent positive resolution $(r=.33)$.

Background analyses. The narrative identity processing dimensions were conceptualized as representing the narrator's subjective interpretation of experience and should therefore be independent of potentially confounding objective factors of the event itself, such as the objective severity of the 
event and the amount of time that has elapsed since the difficult experience. These two factors may be especially critical with respect to coherent positive resolution, as more severe and/or more recent experiences may be more difficult to narrate with a positive conclusion. However, coherent positive resolution was not significantly correlated with event severity $(r=-.14)$ or years since the experience $(r=.19)$, nor was exploratory narrative processing $(r=.17, r=-.16)$ or positive self-transformation $(r=.06, r=.03)$.

\section{Personality Traits}

The personality traits of coping openness and ego-resiliency were measured with scales from the California Psychological Inventory (CPI; Gough, 1987).

Coping openness. The extent to which individuals characteristically engage in an open versus defensive style of coping was assessed at both age 21 and age 52 with a composite scale created by averaging scores on two previously established CPI scales, Tolerance of Ambiguity and Repression (reverse-scored). The Tolerance of Ambiguity and Repression scales are from a set of measures constructed from CPI items by Joffe and Naditch (1977) to assess Haan's (1977) styles of coping and defending. On the open end, tolerance of ambiguity involves the ability to tolerate cognitive and affective complexity and dissonance. In contrast, repression involves defensively forgetting about particular events and experiences from the past. The reliability and validity of these scales has been established (Joffe \& Naditch, 1977) and further demonstrated through their extensive use in previous research (e.g., Helson \& Wink, 1987; Helson \& Srivastava, 2001; Labouvie-Vief \& Medler, 2002). In the current sample, the Tolerance of Ambiguity and Repression (reverse-scored) scales were correlated .60 at age $21($ alpha $=.76)$ and .57 at age $52($ alpha $=.73)$.

Ego-resiliency. Ego-resiliency, defined as the capacity to adapt effectively to challenging life circumstances and maintain a positive outlook, was measured at both age 21 and age 52 with a recently developed CPI scale of ego-resiliency (Klohnen, 1996) that was based on Blocks' (Block \& Block, 1980) observer measure of ego-resiliency. Although the scale was recently developed, it was possible to retroactively score egoresiliency at age 21 and age 52 from the items of the CPI, which was administered at every assessment of the Mills study. As reported elsewhere (Klohnen, 1996), the scale has good internal consistency (alpha $=.88)$ and shows both convergent validity with the observer measure and relations with life-event indicators of resilience. 


\section{Maturity, Life Satisfaction, and Optimal Development}

The outcomes of maturity and life satisfaction were measured at age 61. Maturity was measured with a composite of three ratings made by a clinically trained interviewer following an extensive interview covering thoughts and feelings on many aspects of life, including work, family relationships, health, and aging. The three ratings assessed mature affective response, self-knowledge, and integrity. Each item was rated on a 5-point scale where 1 was low, 3 was average, and 5 was high. These ratings were averaged together to create a Maturity scale (alpha $=.73, \quad M=4.0, \quad S D=.67$ ). Life satisfaction was measured with a single-item scale that asked the question, "Is this time of your life ...?" Participants responded with the following 4-point scale: $1=$ not so good, $2=$ fair, $3=$ good , and $4=$ first-rate. This item ranged from 1 to 4 with an average of $3.34(S D=.71) .{ }^{4}$ Finally, a measure of optimal development at age 61 was created by standardizing the measures of maturity and life satisfaction and averaging them together.

\section{Physical Health}

The primary outcome measure of physical health was a single-item selfreport measure administered at age 61 that asked, "How would you rate your general state of health?" Participants responded with the following 5-point scale: $1=$ poor, $2=$ below average, $3=$ average, $4=$ above average, and $5=$ excellent. Self-reported physical health ranged from 1 to 5 and averaged $4.1(S D=.97)$. An interviewer rating of physical health was also available for a subset $(n=62)$ of the sample. This observer-measure of physical health was based on the same interview used for the maturity ratings (see above) and included several questions about physical health (e.g., Have you ever experienced a major health challenge or chronic health problems?). The interviewers rated physical health on a 7-point scale ranging from 0 (very unhealthy) to 6 (very healthy) and based the rating on the responses to the health questions and their overall impression of the participants' health and vitality. The two measures of health were correlated .64 .

4. Life satisfaction was assessed in a questionnaire that was mailed to the participants as a precursor to the main age 61 assessment. Therefore, it was assessed approximately a year earlier. However, for ease of presentation, I refer to subjective well-being as part of the age 61 assessment. 


\section{RESULTS AND DISCUSSION}

\section{Coping Openness, Exploratory Narrative Processing, and Maturity}

In the first set of hypotheses, coping openness, as measured both before (age 21) and after the difficult life experience (age 52), was expected to predict the exploratory narrative processing of that experience as narrated at age 52. In addition, exploratory narrative processing was expected to mediate the relationship between coping openness at age 21 and maturity at age 61. First, as predicted, exploratory narrative processing was positively correlated with coping openness at age $21(r=.32, p<.01)$ and age $52(r=.28, p<.05)$. This pattern of correlations is consistent with the idea that coping openness shapes narrative identity construction by opening the self up to the cognitive and affective richness of experience that stimulates exploratory narrative processing. Second, the mediation hypothesis was tested by regressing age 61 maturity on both coping openness at age 21 and exploratory narrative processing, with age 21 coping openness entered in the first step and exploratory narrative processing entered in the second step (see Baron \& Kenny, 1986). Consistent with mediation, the effect of coping openness at age 21 on maturity at age $61(\beta=.23, p<.05)$ was reduced to a nonsignificant level $(\beta=.12)$ when the effect of exploratory narrative processing at age $52(\beta=.29, p<.05)$ was taken into account. This mediation effect is depicted in the top half of Figure 1.

The developmental pathway illustrated in the top half of Figure 1 is generally consistent with Staudinger's (2001) theory that life reflection (i.e., broad form of exploratory narrative processing) constitutes a "meta-regulatory" process of development that enhances wisdom and maturity, particularly in the context of reflecting on life's losses, failures, and setbacks. However, the current finding enriches Staudinger's (2001) perspective by incorporating the shaping role of the trait of coping openness. On the one hand, individuals high in coping openness embrace the narrative identity challenge of their difficult experiences and engage in exploratory narrative processing, a process that allows for greater levels of self-understanding, wisdom, and emotional complexity to be incorporated into the life story and enhance maturity over time. In contrast, individuals low in coping openness, who take a more defensive approach to coping, may be 

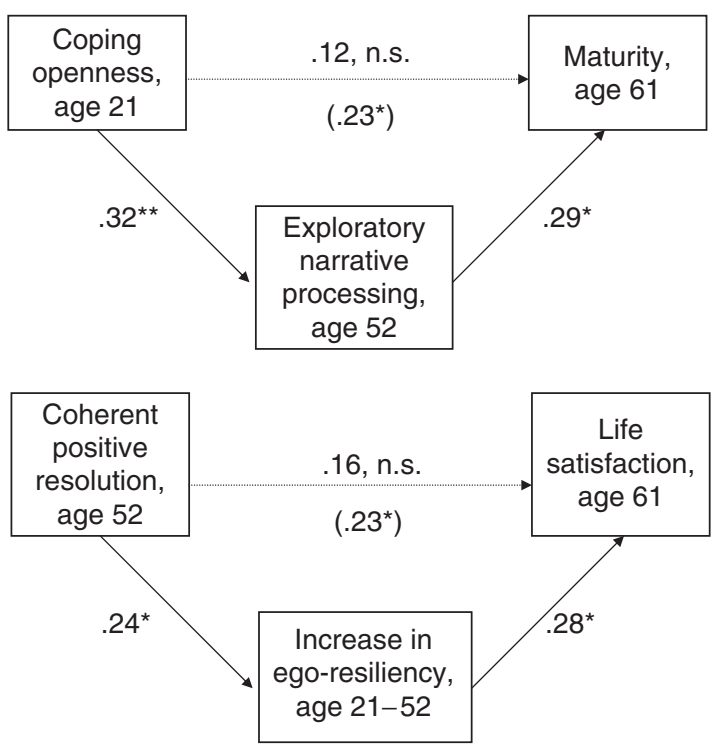

${ }^{*} p \leq .05 ;{ }^{* *} p<.01$.

Figure 1

Patterns of mediation among narrative identity processing dimensions, personality traits, and developmental outcomes of maturity and life satisfaction.

threatened by the identity challenge of difficult experiences and therefore narrate them in a distancing rather than exploratory manner, thus limiting the development of maturity. This finding intriguingly suggests that exploratory narrative processing may operate as a developmental mechanism through which the raw potential for maturity (or lack thereof) within one's traits gets translated into the developmental outcome of maturity as individuals navigate the ups and downs of adult life.

\section{Coherent Positive Resolution, Ego-Resiliency, and Life Satisfaction}

In the second set of hypotheses, coherent positive resolution was expected to be reciprocally related to ego-resiliency between young adulthood and midlife such that ego-resiliency at age 21 would predict coherent positive resolution and coherent positive resolution, in turn, would predict a relative increase in ego-resiliency from age 21 to age 52. In addition, this increase in ego-resiliency was expected 
to mediate the relationship between coherent positive resolution and life satisfaction in late midlife. First, contrary to expectation, age 21 ego-resiliency did not predict coherent positive resolution at age 52 $(r=.04, n s)$. However, coherent positive resolution did correlate positively with age 52 ego-resiliency $(r=.27, p<.05)$ and was positively correlated with a relative change score for ego-resiliency that was calculated by regressing age 52 ego-resiliency on age 21 and saving the residual $(r=.24, p<.05)$. Thus, women who narrated their most difficult and identity-challenging experience with coherent positive resolution displayed a relative increase in ego-resiliency from early adulthood to midlife, whereas women whose narratives lacked a coherent and resolved positive ending displayed a relative decrease in ego-resiliency. Overall, this pattern of findings suggests that ego-resiliency may not yet be fully formed at age 21 and that how people respond to the identity challenge of difficult experiences as they progress through adulthood may be one factor that contributes to the level of ego-resiliency that has emerged by midlife.

Turning to the mediation hypothesis, life satisfaction at age 61 was regressed on both coherent positive resolution and the residual change score for ego-resiliency from 21 to age 52, with coherent positive resolution entered in the first step and the ego-resiliency change score entered in the second step. Consistent with mediation, the effect of coherent positive resolution on life satisfaction at age 61 $(\beta=.23, p=.05)$ was reduced to a nonsignificant level $(\beta=.16)$ when the effect of increased ego-resiliency $(\beta=.28, p<.05)$ was taken into account. The bottom half of Figure 1 illustrates this mediation effect. This finding is consistent with idea that when a person's narrative identity contains the coherent positive resolution of experiences that have challenged identity in the past, the self is strengthened by this memory and made to be more resilient in the face of new challenges, resulting in a sense of satisfaction with how one's life is going. In contrast, if difficult experiences are left unresolved within the story and negative thoughts and feelings linger, the resiliency of self may be weakened, increasing the likelihood of more unresolved difficulties and lowered life satisfaction over time. This developmental pathway may be understood as providing support for Fredrickson's (2001) broaden-and-build theory of positive emotions. This theory asserts that "positive emotions build psychological resiliency and trigger upward spirals toward improved emotional well-being" (p. 223) through their capacity to broaden one's thinking and open 
up new possibilities for thinking, feeling, and behaving. Paralleling this idea, coherent positive resolution may increase ego-resiliency and enhance life satisfaction due to its capacity to move the focus of narrative identity processing away from the narrowing grip of negative emotional experiences and towards new life experiences that generate positive emotion.

The mediational pathway presented above was described with a theoretically driven causal interpretation of how coherent positive resolution, as a process of narrative identity construction, leads to increased ego-resiliency and enhanced life satisfaction over time. Although this interpretation is consistent with several theoretical perspectives on how narrative identity processes may shape behavior and affect development (e.g., Singer \& Blagov, 2004; Bauer et al., 2005), it is also important to note that the directionality of the relationships among coherent positive resolution, increasing ego-resiliency, and life satisfaction remains unknown. Indeed, it could also be the case that generally healthy and optimistic people are more resilient and satisfied with their lives and are therefore better able to look back on difficult life experiences positively, narrating them with coherent positive resolution. This alternative interpretation, which identifies coherent positive resolution as the product rather than the cause of the positive outlook associated with ego-resiliency and subjective well-being, is consistent with research showing that a person's present psychological state affects how he or she recalls past events (e.g., Moffitt, Singer, Nelligan, Carlson, \& Vyse, 1994). However, it is noteworthy that coherent positive resolution was not associated with age 21 ego-resiliency but was associated with increasing ego-resiliency from age 21 to age 52; this pattern suggests that coherent positive resolution is not simply the result of some people being more resilient and positive throughout their adult lives. Rather, it suggests (a) that dynamic changes occur between young adulthood and midlife that affect the development of ego-resiliency and the capacity for subjective well-being and (b) that one of these dynamic changes could be the integration of a coherent and positive ending to a difficult life event into one's developing sense of narrative identity. In sum, although further research is needed in order to determine the direction of causality between the narrative process of coherent positive resolution on the one hand and ego-resiliency and subjective well-being on the other, it may very well be the case that both causal interpretations proposed here are accurate and that 
coherent positive resolution is reciprocally related to resiliency and well-being throughout adulthood.

Positive Self-Transformation, Optimal Development, and Physical Health

In the third set of hypotheses, the integration of exploratory narrative processing and coherent positive resolution was expected to predict the theme of positive self-transformation within narratives of difficult experiences, and positive self-transformation, in turn, was expected to predict optimal development and physical health in late midlife. First, a multiple regression analysis was conducted in which positive self-transformation was regressed on both exploratory narrative processing and coherent positive resolution simultaneously. ${ }^{5}$ As predicted, both exploratory narrative processing $(\beta=.60$, $p<.001)$ and coherent positive resolution $(\beta=.38, p<.001)$ displayed significant contributions to positive self-transformation. This finding suggests that when adults first openly explore the meaning and impact of an identity-challenging experience in terms of its potential to enrich and transform the self, coherent positive resolution then serves to crystallize an enduring sense of positive selftransformation within that person's identity-defining life story. This finding provides support for Calhoun and Tedeschi's (1998) view that narrative plays a critical role in how people come to experience a sense of growth after traumatic events, and suggests, more specifically, that the narrative construction of post-traumatic growth involves a two-step process of first exploring the meaning of the experience and then constructing a coherent and positive conclusion (see also Pals \& McAdams, 2004).

Second, providing further support for the healthy and integrative quality of positive self-transformation, this narrative theme predicted optimal development (the composite of maturity and life satisfaction) at age $61(r=.25, p<.05)$. Moreover, neither exploratory narrative processing $(r=.13, n s)$ nor coherent positive resolution $(r=.11, n s)$ was predictive of optimal development on its own,

5. For this regression analysis, the original exploratory narrative processing and coherent positive resolution scales were used rather than the "pure" scales with the overlapping variance removed. This was done because multiple regression automatically accounts for shared variance and isolates the unique contributions of the predictor variables. 
further suggesting that it is the product of the integration of the two narrative processes, captured by positive self-transformation, that is uniquely associated with optimal development. This finding is consistent with several other recent studies (Bauer \& McAdams, 2004; Bauer et al., 2005; King et al., 2000), which have shown that adults who are both mature and happy narrate their life experiences in ways that grapple with meaning, embrace change, and conclude with a lasting sense of positive growth.

Finally, consistent with expectations, positive self-transformation predicted self-reported physical health at age $61(r=.26, p<.05)$. This finding was further supported by the correlation between positive self-transformation and interviewer-rated physical health at age $61(r=.42, p<.01, n=62)$ and is generally consistent with research showing that the narrative transformation of traumatic experiences through writing has a positive effect on health (Pennebaker \& Seagal, 1999). As with optimal development, neither exploratory narrative processing (.09) nor coherent positive resolution (.11) was predictive of physical health on its own. It is interesting that coherent positive resolution was not predictive despite the fact that there is an established body of research showing that a general psychological and emotional emphasis on the positive is associated with better physical health (Salovey, Rothman, Detweiler, \& Steward, 2000). In the context of narrative identity, it may not be a general emphasis on the positive but rather a sense of being positively transformed by the negative that is most beneficial to physical health.

\section{GENERAL DISCUSSION}

Overall, this study provides support for the idea that the narrative identity processing of difficult life experiences plays a significant role in pathways of personality development and the experience of physical health in adulthood. The general idea that there are two distinct pathways of development, one moving toward maturity and one moving towards well-being, is not new and has been examined extensively in previous studies, including studies also using the Mills Longitudinal Study (see Helson \& Srivastava, 2001; Helson \& Wink, 1987). What the current study adds to this established perspective is a greater understanding of the specific roles of exploratory narrative processing, coherent positive resolution, and positive self-transformation 
within these developmental pathways. Most importantly, these findings highlight (a) the dynamic interplay between narrative identity processing and personality traits, and (b) how this dynamic interplay unfolds between young adulthood and late midlife. Several limitations of this study are discussed below, along with remaining questions, broad implications, and directions for future research on narrative identity.

\section{Limitations of the Current Study}

One limitation of the current study is that the sample was very homogeneous, with participants who were all college-educated women and predominantly white and middle class. Although the homogeneity of the sample allowed for the assessment of individual differences in developmental pathways while essentially holding demographic characteristics constant, an important direction for future research will be to examine the generalizability of these findings to men and to individuals of other cultural and socioeconomic backgrounds. With respect to gender, for example, previous research on coping suggests that women may be more likely than men to engage in the kinds of expressive and openly interpretive coping strategies that would be associated with exploratory narrative processing and positive self-transformation (Tamres, Janicki, \& Helgeson, 2002). However, several recent studies on how the narration of difficult experiences relates to maturity and well-being have used samples that included both women and men (e.g., Bauer \& McAdams, 2004; King et al., 2000) and have not reported any findings that would suggest that there are meaningful gender differences in how exploratory narrative processing and coherent positive resolution shape pathways of personality development. Nonetheless, it is clear that more research is needed to understand fully the ways in which such factors as gender, ethnicity, and socioeconomic background do and do not affect the narrative identity processing of difficult life experiences.

A second limitation of this study is that although the hypotheses reflect theoretically driven ideas about cause-effect relations (e.g., coping openness stimulates exploratory narrative processing; coherent positive resolution leads to increased ego-resiliency), the correlational design did not allow for analyses that would support conclusive statements regarding causality. The longitudinal findings 
were consistent with causal patterns unfolding over time but did not prove them. Thus, an important direction for future research on narrative identity processing will be to examine its causal impact, ideally through studies that closely examine the connection between changes in narrative identity and changes in relevant outcomes. In one recent study, for example, individuals who wrote about a traumatic experience for several days displayed an increase in self-reported personal growth and self-acceptance, whereas those who wrote about trivial topics did not show this pattern of positive self-transformation (Hemenover, 2003). This finding supports the idea that when people fully engage in the narrative processing of a difficult experience, their understanding of themselves and their lives may transform in ways that will make them more mature, resilient, and satisfied with their lives. Findings such as these reflect the growing view that the narrative interpretation of past experiences - the cornerstone of narrative identity - constitutes one way adults may intentionally guide development and bring about change in their lives (Bauer et al., 2005).

A third limitation of this study is something that could also be considered a strength - the variety of different types of experiences reported in the women's narratives. On the one hand, narrative identity is by definition interpretive, so it is important to allow participants to define for themselves exactly what experiences were the most difficult and identity challenging. On the other hand, difficult experiences vary in several ways that may importantly affect narration, such as the life domain (e.g., relationships, career), the role of the narrator in the difficult event (e.g., victim vs. perpetrator), and the severity of the difficult event. As reported above, severity was unrelated to exploratory narrative processing, coherent positive resolution, and positive self-transformation in the current sample. However, severity may be an important factor in narratives of more extreme difficulties and traumas. Indeed, the idea that positive self-transformation is the only healthy way to make sense of a difficult experience is a powerful theme within Western culture that may obscure other equally legitimate and healthy ways of narrating profoundly traumatic experiences (Carney, 2004). Thus, it will be important in future research to examine how such variations in difficult experiences affect narrative identity processing and its developmental implications. 
Do Difficult Life Experiences Play a Unique Role in Narrative Identity?

An underlying assumption of this research is that difficult experiences are identity challenging and therefore play a unique role in narrative identity and personality development. However, it was not possible with the archival data set used here to test explicitly whether narratives of difficult experiences are more centrally involved in the development of maturity and well-being than are narratives of other types of experiences. Although it will be important to directly examine this question in future research, recent studies currently suggest alternative and complementary perspectives on this issue.

On the one hand, the trait-narrative associations between coping openness/exploratory narrative processing and ego-resiliency/coherent positive resolution may be understood as dynamic manifestations of what have been described as fundamental modes of healthy regulation and development in adulthood, affect complexity, and affect optimization (Labouvie-Vief \& Medler, 2002). These modes transcend the narration of difficult life experiences and suggest that two basic, trait-related processes may shape the narrative construction of identity in adulthood, one generally aimed at embracing and actively interpreting the affective complexity of life experiences in order to develop more mature ways of thinking about the self and the world and one generally aimed at identifying and building on the positive aspects of experience in order to maintain well-being. Labouvie-Vief and Medler (2002) showed how these two modes combine to create four distinct regulatory styles, the most healthy being the combination of affect complexity and affect optimization. The current findings suggest that positive self-transformation, which integrated exploratory narrative processing and coherent positive resolution and predicted optimal development, may be one narrative manifestation of this healthy regulatory style operating within the narrative construction of identity.

On the other hand, research also suggests that the narrative identity processing of difficult life experiences may indeed play a uniquely predictive role in the development of maturity and well-being. First, recent studies suggest that exploratory narrative processing and the development of maturity may be more likely to occur in the context of difficult experiences than in the context of positive experiences. For example, McLean and Thorne (2003) found that meaning 
making (i.e., exploratory narrative processing) was more common within self-defining memories that contained conflict than in those that did not. In addition, Pals (2005) found that the growth outcomes associated with negative events within the life story (e.g., wisdom) were more suggestive of exploratory narrative processing and the development of maturity than were the growth outcomes associated with positive events (e.g., clarity of career identity). Second, the finding that the lack of coherent positive resolution was associated with a pattern of decreasing ego-resiliency and low life satisfaction in late midlife highlights the idea that in contrast to positive experiences (which do not require resolution), the narrative interpretation of difficult experiences may be especially important due to its unique potential, if handled ineffectively, to exert an unhealthy and damaging effect on narrative identity and development.

Narrative Identity and Traits: Dynamic Relations Between Two Levels of Personality

Finally, this study highlights several points regarding how to think about the relationship between two distinct levels of personality, traits and narrative identity (McAdams, 2001). First, the trait-narration associations reported here suggest that narrative identity processing should be considered as one domain of psychological behavior in which personality traits manifest themselves. Certainly, other factors (e.g., culture, interpersonal relationships, mood) may shape narrative identity processing as well, but personality traits clearly play a role. Second, as exemplified by the finding that exploratory narrative processing mediated the impact of coping openness on maturity, narrative identity processing should be considered as one mechanism through which personality traits shape pathways of development over time. Third, the finding that coherent positive resolution was predictive of increasing ego-resiliency from young adulthood to midlife suggests that narrative identity processing may operate as a mechanism of personality change in adulthood (see Pals, 1999; Roberts \& Pomerantz, 2004). Put simply, changes and new developments in how people interpret their lives may trigger corresponding changes in enduring patterns of thinking, feeling, and behaving-i.e., personality traits - over time.

In closing, the current study showed that individual differences in the narrative identity processing of difficult experiences were 
dynamically related to personality traits and pathways of personality development that began in young adulthood and continued to late midlife. As captured by the woman in the opening example, the narrative integration of exploratory narrative processing and coherent positive resolution may create an enduring sense of positive selftransformation within narrative identity, fostering a mature sense of well-being that is enriched rather than threatened by the most difficult experiences of adult life. Difficult experiences, as challenges to identity and an inevitable aspect of adulthood, constitute critical building blocks within the life story that not only reflect but may also meaningfully shape how adults progress through their lives.

\section{REFERENCES}

Baerger, D. R., \& McAdams, D. P. (1999). Life story coherence and its relation to psychological well-being. Narrative Inquiry, 9, 69-96.

Baron, R. M., \& Kenny, D. A. (1986). The moderator-mediator variable distinction in social psychological research: Conceptual, strategic and statistical considerations. Journal of Personality and Social Psychology, 51, 1173-1182.

Bauer, J. J., \& McAdams, D. P. (2004). Personal growth in adults' stories of life transitions. Journal of Personality, 72, 573-602.

Bauer, J. J., McAdams, D. P., \& Sakaeda, A. R. (2005). Interpreting the good life: Growth memories in the lives of mature, happy people. Journal of Personality and Social Psychology, 88, 203-217.

Berzonsky, M. D., \& Sullivan, C. (1992). Social-cognitive aspects of identity style: Need for cognition, experiential openness, and introspection. Journal of Adolescent Research, 7, 140-155.

Blagov, P. S., \& Singer, J. A. (2004). Four dimensions of self-defining memories (specificity, meaning, content, and affect) and their relationships to selfrestraint, distress, and repressive defensiveness. Journal of Personality, 72, 481-511.

Block, J. H., \& Block, J. (1980). The role of ego-control and ego-resiliency in the organization of behavior. In W. A. Collins (Ed.), The Minnesota symposia on child psychology (Vol. 13, pp. 39-101). Hillsdale, NJ: Erlbaum.

Calhoun, L. G., \& Tedeschi, R. G. (1998). Posttraumatic growth: Future directions. In R. G. Tedeschi, C. L. Park, \& L. G. Calhoun (Eds.), Posttraumatic growth: Positive changes in the aftermath of crisis (pp. 215-238). Mahwah, NJ: Erlbaum.

Carney, S. K. (2004). Transcendent stories and counternarratives in Holocaust survivor life histories: Searching for meaning in video-testimony archives. In C. Daiute \& C. Lightfoot (Eds.), Narrative analysis: Studying the development of individuals in society (pp. 201-221). Thousand Oaks, CA: Sage Publications.

Cohler, B. J. (1991). The life story and the study of resilience and response to adversity. Journal of Narrative \& Life History, 1, 169-200. 
Conway, M. A., \& Pleydell-Pearce, C. W. (2000). The construction of autobiographical memories in the self-memory system. Psychological Review, 107, 261-288.

Davis, P. J. (1987). Repression and the inaccessibility of affective memories. Journal of Personality and Social Psychology, 53, 585-593.

Davis, P. J. (1995). Repression and the inaccessibility of emotional memories. In J. L. Singer (Ed.), Repression and dissociation: Implications for personality theory, psychopathology, and health (pp. 387-403). Chicago: The University of Chicago Press.

Diener, E., Suh, E. M., Lucas, R. E., \& Smith, H. L. (1999). Subjective well-being: Three decades of progress. Psychological Bulletin, 125, 276-302.

Fredrickson, B. L. (2001). The role of positive emotions in positive psychology: The broaden-and-build theory of positive emotions. American Psychologist, 56, 218-226.

Gough, H. G. (1987). California Psychological Inventory administrator's guide. Palo Alto, CA: Consulting Psychologists Press.

Haan, N. (1977). Coping and defending. New York: Academic Press.

Helson, R. (1967). Personality characteristics and developmental history of creative college women. Genetic Psychology Monographs, 76, 205-256.

Helson, R. (1992). Women's difficult times and the rewriting of the life story. Psychology of Women Quarterly, 16, 331-347.

Helson, R., \& Srivastava, S. (2001). Three paths of adult development: Conservers, seekers, and achievers. Journal of Personality and Social Psychology, 80, 995-1010.

Helson, R., \& Wink, P. (1987). Two conceptions of maturity examined in the findings of a longitudinal study. Journal of Personality and Social Psychology, 53, 531-541.

Hemenover, S. H. (2003). The good, the bad, and the healthy: Impacts of emotional disclosure of trauma on resilient self-concept and psychological distress. Personality and Social Psychology Bulletin, 29, 1236-1244.

Janoff-Bulman, R. (1992). Shattered assumptions: Towards a new psychology of trauma. New York: Free Press.

Joffe, P. E., \& Naditsch, M. (1977). Paper and pencil measures of coping and defending processes. In N. Haan (Ed.), Coping and defending (pp. 280-298). New York: Academic Press.

King, L. A. (2001). The hard road to the good life: The happy, mature person. Journal of Humanistic Psychology, 41, 51-73.

King, L. A., \& Raspin, C. (2004). Lost and found possible selves, subjective wellbeing, and ego development in divorced women. Journal of Personality, 72, 603-632.

King, L. A., Scollon, C. K., Ramsey, C., \& Williams, T. (2000). Stories of life transition: Subjective well-being and ego development in parents of children with Down Syndrome. Journal of Research in Personality, 34, 509-536.

Klohnen, E. C. (1996). Conceptual analysis and measurement of the construct of ego-resiliency. Journal of Personality and Social Psychology, 70, 1067-1079. 
Labouvie-Vief, G., \& Medler, M. (2002). Affect optimization and affect complexity: Modes and styles of regulation in adulthood. Psychology and Aging, 17, 571-588.

Loevinger, J. (1976). Ego development: Conceptions and theories. San Francisco: Jossey-Bass.

McAdams, D. P. (1985). Power, intimacy, and the life story. New York: Guilford Press.

McAdams, D. P. (2001). The psychology of life stories. Review of General Psychology, 5, 100-122.

McAdams, D. P., Anyidoho, N. A., Brown, C., Huang, Y. T., Kaplan, B., \& Machado, M. (2004). Traits and stories: Links between dispositional and narrative features of personality. Journal of Personality, 72, 761-784.

McAdams, D. P., Booth, L., \& Selvik, R. (1981). Religious identity among students at a private college: Social motives, ego stage, and development. MerrillPalmer Quarterly, 27, 219-239.

McAdams, D. P., Reynolds, J., Lewis, M., Patten, A. H., \& Bowman, P. J. (2001). When bad things turn good and good things turn bad: Sequences of redemption and contamination in life narrative and their relation to psychosocial adaptation in midlife adults and in students. Personality and Social Psychology Bulletin, 27, 474-485.

McLean, K. C., \& Thorne, A. (2003). Late adolescents' self-defining memories about relationships. Developmental Psychology, 39, 635-645.

Moffitt, K. H., Singer, J. A., Nelligan, D. W., Carlson, M. A., \& Vyse, S. A. (1994). Depression and memory narrative type. Journal of Abnormal Psychology, 103, 581-583.

Pals, J. L. (1999). Identity consolidation in early adulthood: Relations with egoresiliency, the context of marriage, and personality change. Journal of Personality, 67, 295-329.

Pals, J. L. (2005, January). Constructing growth: Causal connections between past events and self within the life story. Poster presented at the 6th Annual Meeting of the Society of Personality and Social Psychology, New Orleans, LA.

Pals, J. L., \& McAdams, D. P. (2004). The transformed self: A narrative understanding of posttraumatic growth. Psychological Inquiry, 15, 65-69.

Pennebaker, J. W. (1997). Writing about emotional experiences as a therapeutic process. Psychological Science, 8, 162-166.

Pennebaker, J. W., \& Seagal, J. D. (1999). Forming a story: The health benefits of narrative. Journal of Clinical Psychology, 55, 1243-1254.

Pillemer, D. B. (2001). Momentous events and the life story. Review of General Psychology, 5, 123-134.

Roberts, B. W., \& Pomerantz, E. M. (2004). On traits, situations, and their integration: A developmental perspective. Personality and Social Psychology Review, 8, 402-416.

Salovey, P., Rothman, A. J., Detweiler, J. B., \& Steward, W. T. (2000). Emotional states and physical health. American Psychologist, 55, 110-121.

Singer, J. A. (2004). Narrative identity and meaning-making across the lifespan: An introduction. Journal of Personality, 72, 437-460. 
Singer, J. A., \& Blagov, P. (2004). The integrative function of narrative processing: Autobiographical memory, self-defining memories, and the life story of identity. In D. R. Bieke \& J. M. Lampinen, et al. (Eds.), The self and memory. Studies in self and identity (pp. 117-138). New York: The Psychology Press.

Singer, J. A., King, L. A., Green, M. C., \& Barr, S. C. (2002). Personal identity and civic responsibility: "Rising to the occasion" narratives and generativity in community action student interns. Journal of Social Issues, 58, 535-556.

Singer, J. A., \& Salovey, P. (1993). The remembered self: Emotion and memory in personality. New York: Free Press.

Staudinger, U. M. (2001). Life reflection: A social-cognitive analysis of life review. Review of General Psychology, 5, 148-160.

Tamres, L. K., Janicki, D., \& Helgeson, V. S. (2002). Sex differences in coping behavior: A meta-analytic review and examination of relative coping. Personality and Social Psychology Review, 6, 2-30.

Tugade, M. M., \& Fredrickson, B. L. (2004). Resilient individuals use positive emotions to bounce back from negative emotional experiences. Journal of Personality and Social Psychology, 86, 320-333. 
1110 